\title{
¿La comunicabilidad operativa de la persona requiere su comunicabilidad ontológica? Discusión sobre un dogma filosófico de nuestro tiempo
}

\author{
Does the Operative Communicability of the \\ Person Require his Ontological Communicability? \\ Discussion on a Philosophical Dogma of our Time
}

\author{
JUAN PABLO ROLDÁN \\ Universidad del Norte Santo Tomás de Aquino \\ jproldanr@gmail.com \\ ORCID: 0000-0002-9368-8216
}

\begin{abstract}
La idea de que una filosofía de la persona substancialista e individualista ha atravesado toda la metafísica occidental y ha constituido un obstáculo para pensar la comunión y la intersubjetividad, se ha convertido en un lugar común del pensamiento contemporáneo. Se problematiza aquí esta perspectiva. Se sugiere que sus distintas formulaciones, muy variadas, obedecieron a un argumento similar, dependiente también de fundamentos teóricos muy cercanos entre sí. Se compara este planteo con el del personalismo ontológico y se evalúan los resultados del intento llamado "postmetafísico" de alcanzar una filosofía de la comunión superando el humanismo. Autores variados como Schopenhauer, Nietzsche, Freud, Heidegger, Foucault, Vattimo, Esposito, Butler, Scheler, entre otros, son referidos para ilustrar el debate.
\end{abstract}


Palabras clave: persona; substancia; intersubjetividad; metafísica; postmetafísica; fenomenología.

\begin{abstract}
The idea that a substantialist and individualistic philosophy of the person has permeated all of Western metaphysics and has been an obstacle to thinking about communion and intersubjectivity, has become commonplace in contemporary thought. This perspective is problematized here. It is suggested that its different formulations, though varied, obeyed a similar argument and dependence on closely related theoretical foundations. This approach is compared with that of ontological personalism and the results of the so-called "post-metaphysical" attempt to achieve a philosophy of communion that overcomes humanism. Interaction with various authors such as Schopenhauer, Nietzsche, Freud, Heidegger, Foucault, Vattimo, Esposito, Butler, Scheler, among others, illustrate the debate.
\end{abstract}

Keywords: person; substance; intersubjectivity; metaphysics; postmetaphysics; phenomenology.

Gianni Vattimo ha insistido en la importancia de "pensar el ser fuera de la metafísica de la objetividad por razones éticas” (Vattimo 1996, 45). El sujeto moderno, que declama haber descubierto un orden objetivo, en realidad impone con violencia estructuras artificiales a un ser que es histórico y huidizo de toda conceptualización. De aquí que, en nombre del respeto por los otros, la primacía de la verdad debería ser reemplazada por la de la "caritas", y el ser, entendido por siglos como estático e intemporal, debería ser pensado como "Ereignis" o acontecimiento histórico. Ambos procesos son inseparables: la superación de la metafísica ha sido la condición indispensable para que la filosofía actual pudiera otorgar un papel central al "Otro" (Vattimo 2004, 142).

Los argumentos de Vattimo expresan una idea recurrente en el pensamiento contemporáneo. La tesis de que una concepción de la persona substancialista e individualista ha atravesado toda la metafísica occidental y ha constituido un obstáculo para pensar la comunión y la intersubjetividad, se ha extendido casi como un dogma aceptado acríticamente. Conforme a él, la metafísica, como naturalización del dominio y el control, ha caracterizado al sujeto racional como persona, en un proceso continuo desde la antigüedad hasta la modernidad. El imperativo ético de la “deconstrucción” (Derrida 1986, 60) de la metafísica, por lo tanto, exige 
la superación de este "humanismo" (Heidegger 2006). El término deconstrucción se basa, a su vez, en el concepto Destruktion de Heidegger (Heidegger 1997, 43-49), referido también a la superación de la metafísica.

Estas líneas se proponen analizar esta perspectiva, que podría ser formulada de la siguiente forma en términos fenomenológicos (Crosby 1996): "la comunicabilidad operativa de la persona - o del ser humano - requiere su comunicabilidad ontológica”. En otras palabras, conforme a este planteo existiría un paralelismo entre los niveles operativo y ontológico de un ser humano, de tal manera que la idea de una mayor comunicabilidad operativa (por ejemplo, a través del conocimiento y el amor) exigiría la de una mayor comunicabilidad ontológica (esto es, entender al ser humano como menos individual).

La evidencia de esta tesis será problematizada, en primer lugar, intentando describir su fundamento teórico y su origen histórico. Se propondrá la hipótesis de que las distintas expresiones de esta idea son animadas por un argumento común, que presentaría algunos aspectos vulnerables.

Asimismo, se discutirá si la verdadera disyuntiva filosófica sobre esta cuestión es la que existe entre una concepción metafísica y otra postmetafísica - como plantea este "dogma" - o, por el contrario, la que puede plantearse entre una metafísica monista - como la del siglo XIX- y otra personalista - como la que se dio a comienzos del siglo XX y que fuera criticada por la postmetafísica-.

\section{1. ¿Un argumento común a todos los planteos postmetafísicos?}

Si bien la idea de la necesidad de una superación de la metafísica de la persona suele plantearse como una evidencia indiscutible, tal vez sea posible analizar el proceso discursivo que le da origen y sus supuestos filosóficos. Se propone la hipótesis de que las distintas versiones de esta perspectiva respetan una similar estructura argumental:

1) Una crítica de las ideas antropológicas y metafísicas iluministas y románticas, basadas en el imperativo del dominio del mundo y del ser humano, y en la primacía de lo impersonal y genérico. 
2) Un análisis filosófico y una periodización histórica conforme a los cuales la Ilustración sería el punto de llegada de toda la metafísica occidental.

3) La consiguiente crítica de toda metafísica posible y de sus connaturales ideas de verdad y de sujeto personal.

4) La propuesta positiva de una concepción postmetafísica del mundo, del ser humano y de la sociedad.

\subsection{Crítica de la Ilustración y del Romanticismo}

Si bien el Romanticismo filosófico constituyó, en un principio, una reacción a los ideales ilustrados, en buena medida terminó continuándolos y profundizándolos. El iluminismo consideró el dominio como la clave de la existencia (Adorno y Horkheimer 1998, 59) y dejó de lado el ideal clásico de la primacía de la contemplación. Esta mentalidad, dirigida hacia el interior del ser humano, generó una concepción antropológica dualista. Todo hombre estaría formado por una dimensión pasional profunda, que debería ser dominada por la voluntad humana (Adorno y Horkheimer, 1998, 129-163). La Crítica de la Razón Pura y la Crítica de la Razón Práctica kantianas constituyen un buen ejemplo de ambas ideas.

La filosofía del siglo XIX, más allá de sus aspectos reactivos, extendió y radicalizó esta visión del hombre. Arthur Schopenhauer, por ejemplo, ubicó en el núcleo de los seres humanos, la fuerza impersonal e irresistible de la "Voluntad" genérica, última dimensión de la realidad. La "representación”, en cambio, equivalente al entendimiento kantiano, sólo podía configurar de forma extrínseca los fenómenos percibidos (Schopenhauer 2008). Friedrich Nietzsche, por su parte, compartió esta idea dualista del hombre, sólo que con un matiz de heroicidad romántica. Nietzsche fue algo así como un schopenhaueriano de izquierda.

Las ideas de Darwin, que tenían una carga implícita de filosofía, pronto convergieron con la filosofía romántica. En efecto, Darwin ponía como motor de la realidad las fuerzas impersonales de la especie y de la naturaleza, las cuales, mediante la selección natural avanzaban sin cuidarse de los individuos. Autores como Ernst Haeckel o Eduard von Hartman, de gran éxito en su época, pretendieron haber unido la filosofía con la biolo- 
gía y las neurociencias de su época (Herman 1998, 115-150; Roldán 2019, 55-63).

El positivismo, por su parte, fue una concepción filosófica hostil a la misma filosofía. Era animado por una explícita metafísica monista, tomada del Romanticismo. Existía, para él, un proceso de progreso necesario en la historia, respecto del cual los individuos eran sólo ocasiones.

Todas estas ideas, descriptas en una más que apretada síntesis, coincidían en afirmar la primacía del Todo sobre el individuo y, por consiguiente, la de lo inferior y genérico del ser humano sobre su instancia superior e individual, a pesar del intento de ésta por dominarlo. Sea que se reivindique la racionalidad completa (Hegel) o que se desenmascare la dimensión oculta de los hombres (Schopenhauer), existe una escisión constitutiva entre estas dimensiones (Esposito 2009, 110). De aquí que el monismo metafísico y el dualismo antropológico hayan sido sus tesis fundamentales. La lucha entre las dimensiones inferiores y las superiores de la persona es el reflejo de la lucha entre el Todo y los seres finitos que ha tematizado el Romanticismo.

Esta primacía de lo impersonal vuelve imposibles las relaciones personales auténticas. Las perspectivas ilustradas y románticas convenían en la tesis de la comunicabilidad ontológica (porque el núcleo de los seres humanos, conforme a ellas, no era individual y espiritual) y, por lo tanto, también en la de la incomunicabilidad operativa (ya que toda relación entre dos seres humanos obedecía de forma inconsciente al "genio de la especie” - según la expresión de Schopenhauer-, aunque se creyera a nivel consciente que brotaba de un interés real por la persona del otro).

La inspiración ética de la crítica postmetafísica de la noción de persona se hace presente en este primer paso de la argumentación, para comenzar a desaparecer en el segundo y ser negada, paradójicamente, en los últimos dos. Sin embargo, en esta primera instancia, los autores posmodernos denuncian las consecuencias devastadoras de estas ideas para la vida social: han dado lugar tanto a la "biopolítica decimonónica" - con su "darwinismo social" y su propuesta de eugenesia- como a la "tanatopolítica nazi” (Esposito 2009, 108) o a la sociedad de dominio totalitario de la técnica anunciada por Heidegger (Vattimo 1986, 49-50). 


\subsection{Periodización histórica, metafísica e Ilustración}

Estos postulados hostiles a la humanidad, de tan graves consecuencias prácticas, recibieron una vigorosa respuesta. Entre fines del siglo XIX y principios del XX una serie de pensadores reaccionó tanto a la idea del dominio "hacia adentro" - dualismo antropológico- como a la idea del dominio "hacia afuera", contrario a la contemplación. De modo sintético, podría decirse que el existencialismo realizó la primera de estas críticas, mientras que la fenomenología, la segunda.

La crítica al sujeto del dualismo dio paso a la idea de una persona individual, en la que lo más profundo era lo superior, lo espiritual, único e irrepetible (incomunicabilidad ontológica) que se relacionaba con un mundo de sentido, de esencias y valores en un horizonte de intersubjetividad (comunicabilidad operativa). Esta impugnación personalista del pensamiento del siglo XIX, de significativas consecuencias en el ámbito de las ciencias humanas, no satisfizo a la naciente concepción postmetafísica, a pesar de que ambas compartieran el objetivo de combatir el eje filosófico ilustrado-romántico. Sucede que, conforme a la interpretación postmetafísica, el pensamiento personalista habría fortalecido aquellas ideas que aspiraba a criticar.

Tal concepción depende de la periodización histórica propuesta por Heidegger, y se basa, a su vez, por lo menos en dos presupuestos teóricos. Al rechazar lo dado y proponer su proyecto técnico sobre el mundo, la Ilustración no habría postulado una inversión del pensamiento clásico sino su continuación, profundización y acabamiento. No habría acaecido entre ambos una ruptura real, sino sólo una aparente.

Nietzsche habría sido el "último metafísico de Occidente" (Heidegger 2013, 386), el punto de llegada de toda la metafísica - es decir, no sólo de la racionalista y romántica - y, al mismo tiempo, el encargado de desenmascararla. Los griegos hablaban de contemplación de la verdad, pero, en el fondo, su voluntad de verdad encubría una "voluntad de poder". Es que la centralidad de la consciencia, lejos de ser natural, obedece al propósito de afianzar los objetivos de una mentalidad determinada, basada en el dominio (Vattimo 1986, 46). La consciencia ni siquiera es la instancia de- 
cisiva de la vida humana. Los hombres, lejos de poseer una natural unidad y una integración que brota del espíritu, están conformados por un conjunto de pulsiones enfrentadas (Vattimo 1986, 47), de tal forma que, en realidad, el inconsciente sería la instancia humana decisiva (Vattimo 1986, 49).

Cabe destacar que Nietzsche opta por una visión del ser humano cuyo “yo no es el amo de su propia casa" (Freud 2003, 2436), porque asume con entusiasmo la antropología dualista del siglo XIX. Es significativo que los autores postmetafísicos compartan esta perspectiva en el contexto de su crítica a esa misma filosofía romántica.

He aquí el primer argumento teórico: el sujeto consciente y conocedor objetivo del mundo propuesto por el iluminismo, en realidad es una instancia superficial, débil y secundaria frente a un fondo pulsional. Esta tesis, por otra parte, es similar a la del pensamiento decimonónico.

Vattimo opina que el segundo argumento teórico en favor de esta periodización proviene de Heidegger. Consiste en que el sujeto consciente, que se creía libre, en realidad depende radicalmente del "mundo histórico-social" (Vattimo 1986, 55). De aquí la insistencia de Heidegger en el tema del lenguaje y, también, una explicación de la relación entre Heidegger y el nazismo. Su aprobación del régimen no habría derivado de una preferencia política contingente sino de su perspectiva filosófica. Oponerse al régimen habría significado privilegiar "exigencias y valores... personalistas". El "verdadero elemento positivo" de la actitud de Heidegger, por el contrario, consiste en acatar con lucidez la superioridad de los "poderes suprapersonales”, que percibía “de modo más radical que cualquier otro, quizás incluso más que los mismos pensadores marxistas” (Vattimo 1986, 54-55).

Ambos argumentos son convergentes. La Ilustración sería el punto de llegada de toda la metafísica occidental porque, primero, ésta se habría basado en la falsa primacía de la consciencia, desenmascarada por el descubrimiento del inconsciente - momento nietzschiano- y, segundo, porque esta entronización de la instancia superior del ser humano no sería natural, sino que habría obedecido al cumplimiento de los fines de un proyecto cultural de dominio técnico del mundo - momento heideggeriano-. 


\subsection{Crítica de la metafísica}

$\mathrm{Si}$, en el fondo, hablar sobre el ser o la verdad es una cuestión de poder, la metafísica es inseparable de la violencia. Si se quisiera superar esa violencia, habría que "deconstruir" toda metafísica posible, y no sólo cierto tipo de metafísica.

La idea de persona, de raíz griega y, sobre todo, romana, que fue consolidándose en Occidente desde la antigüedad y que fue profundizada por el cristianismo, sería el dispositivo metafísico fundamental de este proyecto de dominio. Es que "lo particular y propio de toda metafísica se revela en el hecho de que es «humanista»" y, por lo tanto, "todo humanismo sigue siendo metafísico" (Heidegger 2000, 24).

A lo largo de la historia de Occidente, este concepto habría sido naturalizado y considerado el valor central de su cultura. Sin embargo, el ojo avizor postmetafísico habría descubierto su carácter de impostura. La noción "clásico-cristiana de persona", lejos de alumbrar el auténtico valor del ser humano, procedería del proyecto político del hombre europeo, cuyo ideal de dominio del mundo se disimularía en la "pasión por la verdad" y en el sometimiento de todas sus dimensiones a la dirección de la consciencia (Vattimo 1986, 47). La idea moderna y secularizada de persona tendría el mismo origen, y compartiría su "hipoteca cristiana” oculta (Esposito 2009, 106).

El cristianismo y la Ilustración coincidirían en afirmar que el carácter de persona de los seres humanos radicaría en su capacidad "de gobernar, de dominar su propia vida animal” (Esposito 2009, 113). Aristóteles habría adelantado esta perspectiva en su definición de hombre como "animal racional" (Esposito 2009, 132): lo propio de la persona es la racionalidad, que tanto objetiva la realidad (con su pretendida búsqueda de la verdad) como domina su dimensión animal profunda. La idea metafísica de persona, por lo tanto, sería convertible con la del dualismo antropológico. Puede afirmarse que, en general, la postmetafísica identifica el personalismo con un dualismo de lo alto, esto es, con una teoría que propone el dominio de la dimensión inferior y profunda del ser humano por su instancia superior y, al mismo tiempo, superficial. 
Superar la metafísica significará dejar atrás, sobre todo, la idea de un sujeto consistente - "substancial" - personal, consciente, la clave de cuya vida resida en conocer la verdad y apreciar los valores. Esta crítica de la metafísica se nutre de la periodización heideggeriana de la historia de la filosofía, basada en los dos argumentos teóricos formulados más arriba. Pero tal vez exista otro factor que haya potenciado los anteriores: la identificación de la metafísica, en general, con una transformación histórica particular de ésta. Durante los siglos XVI y XVII se desarrolló un importante movimiento filosófico y teológico, llamado Segunda Escolástica - el término fue creado por Carlo Giacon - que influyó de forma significativa en la filosofía moderna. Este ascendiente fue ignorado por mucho tiempo por la historiografía de origen iluminista y hegeliano, interesada en desconocer la relevancia de un movimiento de raíces teológicas en un período filosófico que caracterizaba como frontalmente opuesto a la mentalidad medieval.

Heidegger, en cambio, no sólo tuvo consciencia de la irradiación de las ideas metafísicas de Francisco Suárez - uno de los autores más representativos de la Segunda Escolástica- sobre la filosofía moderna, sino que consideraba que aquellas representaban "lo esencial de la ontología griega" (Heidegger 1997, 46). Pero lo cierto es que la Segunda Escolástica ofreció una versión de ciertos aspectos de la metafísica muy distinta de la que presentaba lo que podría llamarse metafísica clásica (antigua y medieval), aunque utilizara una terminología filosófica similar (Giacon 1946).

En síntesis, podría decirse que radicalizó el aspecto racional discursivo - en detrimento de la intuición- y privilegió una nueva versión del aristotelismo, ahora opuesto al platonismo. De aquí que haya olvidado una clave de la metafísica clásica, de cuño platónico, como la doctrina de la participación.

Las siguientes son algunas tesis que han sido atribuidas a la metafísica en general por el pensamiento contemporáneo, aunque, en realidad, hayan derivado de los planteos de la Segunda Escolástica:

- Existe una oposición entre la substancia y el cambio - idea derivada de una nueva forma de entender las nociones de acto y potencia-. 
De aquí en más, todo "substancialismo" será considerado hostil al dinamismo de la vida.

- De manera análoga, el concepto de substancia es incompatible con los de relacionalidad y subjetividad.

- La materia es oscura, ajena al sentido e impenetrable para la inteligencia. Por lo tanto, no puede dar sustento a ninguna identidad de nivel superior. Quien quisiera explicar la vida del espíritu, debería dar la espalda a la materia y, recién en un segundo momento, preguntarse por su posible relación con el mundo físico.

- No hay continuidad entre las distintas dimensiones humanas - tradicionalmente entendida a modo de participación - sino, más bien, oposición. El conocimiento humano, por lo tanto, no supone un vínculo íntimo con lo conocido, sino la producción de una idea externa al objeto conocido con el fin de poseerlo.

\subsection{Propuesta de un pensamiento postmetafísico}

Los autores postmetafísicos suelen dedicar una mayor extensión al momento destructivo de su argumentación que a la propuesta de un pensamiento propio y no-metafísico ¿Cómo pensar luego de la crítica de un sujeto personal?

Heidegger apeló a un lenguaje sugestivo, poético y ambiguo para expresar su propuesta postmetafísica. Desde la llamada Kehre abandonó los temas existencialistas - o personalistas - como los de la angustia o la autenticidad (Vattimo 1986, 50), porque supondrían la referencia a un sujeto con una identidad individual consistente. Sin embargo, advirtió que esta oposición al humanismo no implicaba ni una defensa "de la inhumanidad" ni un intento de rebajar "la dignidad humana", sino un rechazo de las ideas de "sujeto", "substancia" y "objetividad" aplicadas al ser humano y a su forma de relacionarse con el mundo (Heidegger 2000, 38) ¿Esto significa que Heidegger ha criticado la metafísica humanista porque no daba acabada cuenta de la centralidad y del valor de la persona humana? No.

Ni Nietzsche ni Heidegger habrían atacado la metafísica de la persona en nombre de un "hiperhumanismo" - habida cuenta del humanismo fallido que criticaban- ni tampoco habrían buscado un "impersonalismo" 
- como ha propuesto, entre otros movimientos, el estructuralismo - (Vattimo 1986, 56) ¿Existe algún punto intermedio posible entre una defensa de la persona y una afirmación de la primacía de lo genérico e impersonal? ¿Es la propuesta postmetafísica un intento de hallar ese punto medio?

Desde una perspectiva teórica, las alternativas son excluyentes: ese pretendido punto de balance se acercaría por necesidad a uno de los dos extremos. En el caso de Heidegger, su rechazo del humanismo se alimenta de su énfasis en el horizonte histórico, en el que se revela el ser. No sin razón se ha señalado con frecuencia la presencia velada del monismo hegeliano en esta idea.

Esposito, por su parte, no tiene reparos en identificar la salida postmetafísica con la propuesta de la primacía ontológica de lo impersonal. Considera que Gilles Deleuze ha sido quien mejor ha expresado esta alternativa. Deleuze habría condensado conceptos de Kojeve, Blanchot y Foucault, e intentado una "deconstrucción sistemática de todas las posibles expresiones de la categoría de persona”. No habría tenido la ingenuidad de reemplazar la noción de persona por la de otra realidad metafísica, sino que habría alcanzado "una rotación de todo el horizonte filosófico, en dirección a una teoría del acontecimiento preindividual e impersonal" (Esposito 2009, 204). Cabe destacar, sin embargo, que las últimas obras de Michel Foucault tal vez puedan leerse como un intento de recuperación de algunas tesis personalistas como solución de las aporías del impersonalismo postmetafísico. En ellas, por ejemplo, Foucault propone el "cuidado de sí mismo", valora la ética como "práctica de la libertad” y el "coraje de la verdad”, etc. (Foucault 1994, 2009, 2010).

Judith Butler (Butler 2009), a su vez, piensa que debe superarse el substancialismo. Al criticar la propuesta de Ricoeur de una identidad narrativa (Ricoeur 2006) - que podría ser vista como un intento de vincular la ontología de la persona con la relacionalidad, habida cuenta de la crítica contemporánea a la metafísica-, puntualiza que todo relato se origina en una escena previa, opaca, que depende de lo otro. Lo personal, para ella, ya no sería la clave de la realidad, sino que, como para Deleuze, lo impersonal sería previo y decisivo para entender a cada ser humano (Butler 2009, 
113), ya que lo auténticamente relacional se opondría por definición a la individualidad ontológica.

Cabe preguntarse hasta qué punto estas propuestas constituyen una verdadera crítica de una concepción violenta de la realidad que imposibilite las relaciones sociales o, por el contrario, y paradójicamente, implican su radicalización. Vattimo, por ejemplo, reconoce que esta superación del iluminismo consiste, en realidad, en una profundización del mismo (Vattimo 2001). La filosofía del siglo XIX, con su metafísica monista y su antropología dualista, parece estar presente en gran parte de las ideas postmetafísicas. Su discurso moral, que anima los primeros pasos de sus argumentos contrarios a una metafísica de la persona, presenta una ambigüedad constitutiva. Intenta "decir sin decir": al criticar la violencia y el individualismo, parecería apelar al fundamento de la dignidad absoluta de la persona, pero, por otra parte, rechaza finalmente esa idea de forma explícita. De esta manera, en apariencia traiciona su inspiración principal.

\section{El personalismo incomprendido}

La referida reacción personalista a la filosofía ilustrada y romántica no debería ser entendida como un dualismo de lo alto, al estilo del kantiano - con el que la postmetafisica la identifica-.

Antes de su última peripecia vital e intelectual, Max Scheler encarnó de forma muy particular este cambio de paradigma. Un hilo conductor de su obra fue la defensa de la incomunicabilidad ontológica, y de su relación con la comunicabilidad operativa, así como una clara consciencia de la alternativa que, en cada caso, implicaban las tesis opuestas. Es de notar que su lucidez para comprender esta gran opción metafísica, tal vez haya sido uno de los motivos del giro de sus últimos años. En efecto, abandonando las convicciones que había custodiado, asumió con fría claridad las tesis románticas que había rechazado antes (Scheler, 2003).

En Esencia y formas de la simpatía, Scheler afirma que las personas son “individuos absolutos" (Scheler 2004, 89) y, por eso, capaces de un "amor también absoluto” (Scheler 2004, 214), incompatible con una “interpretación metafísico-monista" (Scheler 2004, 87). De esta forma, el amor "im- 
plica justamente «entrar» en la individualidad ajena... como individualidad ajena y distinta", así como afirmar de forma "calurosa y sin reservas (...) «su» realidad y «su» esencia” (Scheler 2004, 95).

Scheler - como Edith Stein y tantos otros autores - no entiende que alguien se constituya como persona por el dominio de su animalidad ni que la relación con los otros deba estar mediada por una actitud de dominio. Su personalismo ontológico (las personas son individuos absolutos y, por lo tanto, son capaces de un amor absoluto) se encuentra en las antípodas de esa concepción.

\section{Algunas conclusiones}

La tesis de que existe un paralelismo entre la comunicabilidad operativa y la comunicabilidad ontológica no es evidente. Necesita ser fundamentada. Por este motivo, habría que "desnaturalizarla" o "deconstruirla", en el sentido de hacer patente que no se trata de una obviedad natural sino de una construcción cultural.

Además, esta construcción cultural parece ir a contramano de la historia de la filosofía. Esta convence, más bien, de que fue mayoritaria la idea de que la comunicabilidad operativa requiere incomunicabilidad ontológica. Si esto fuera correcto, la verdadera opción metafísica sería la que enfrenta a una filosofía monista en lo metafísico y dualista en lo antropológico - que sostiene, en otras palabras, la comunicabilidad ontológica y la incomunicabilidad operativa de los seres humanos-, con otra creacionista en lo metafísico y personalista en lo antropológico - que postula la incomunicabilidad ontológica como base de la comunicabilidad operativa-. Entre los planteos ilustrados y los postmetafísicos habría, por el contrario, continuidad y afinidad teórica. No habría fundamento teórico ni histórico para sostener que las alternativas contrapuestas son la de la incomunicabilidad ontológica y operativa (basada en una incorrecta identificación del personalismo con el dualismo de lo alto) frente a la de la comunicabilidad ontológica y operativa (tesis proclamada por la postmetafísica por los motivos apuntados y con cierta inconsistencia, resuelta hacia la incomunicabilidad operativa). 
Por lo demás, la crítica postmetafísica de la Ilustración parece ser ambigua: rechaza su violencia y su falta de humanidad, pero llama a reforzar los principios iluministas como solución a sus consecuencias. Descarta el personalismo por considerarlo cómplice del iluminismo (que lo habría desenmascarado) cuando, por otra parte, encuentra en la ilustración potenciada el destino necesario y deseable de la humanidad. Difunde la idea del paralelismo entre comunicabilidad metafísica y operativa con el mecanismo de la naturalización, mecanismo que había criticado en el pensamiento clásico.

Esta naturalización de los argumentos postmetafísicos ha llevado a que en la actualidad sea usual el debate entre la mentalidad ilustrada (conservadora, defensora de la libertad, el orden y el progreso científico y económico) y la actitud posmoderna (progresista, defensora de la humanidad y la solidaridad), dando lugar a una dialéctica entre extremos comprometidos teóricamente entre sí. La defensa de la ilustración por parte de Steven Pinker (Pinker 2018), la crítica de la empatía - concepto de importancia fundamental para el personalismo - por Paul Bloom (Bloom 2016) o la explicación desde el darwinismo de una realidad humana como el lenguaje, por parte de ambos (Pinker y Bloom 1990), podrían ser algunos ejemplos de esta dialéctica.

Puede descubrirse un argumento común a todos los planteos postmetafísicos. Este argumento se estructuraría en por lo menos cuatro pasos. En los primeros, estaría presente la inspiración ética de la postmetafísica. En los últimos, ésta debería ser abandonada, por lo que la explicación perdería consistencia. Tanto la periodización histórica de Heidegger, que ve en Nietzsche al "último metafísico", como los conceptos metafísicos de la Segunda Escolástica, ocuparían un lugar relevante - explícito en un caso e implícito en el otro - en este argumento.

En cualquier caso, la postmetafísica desconoce o desfigura la idea central del personalismo ontológico. De alguna manera, pretende ingresar al siglo XXI saltando el XX y, así, retorna al XIX. Esta trama dramática sobre la relación entre la comunicabilidad y la incomunicabilidad, en la que actúan el dualismo de lo alto, el dualismo de lo bajo, el personalismo ontológico y un retorno postmetafísico a la primacía de lo genérico e imperso- 
nal, podría ser una clave hermenéutica para varias discusiones filosóficas e interdisciplinarias contemporáneas. Por ejemplo, en las polémicas propias del psicoanálisis postfreudiano - en las que se intenta discernir entre el método psicoterapéutico de Freud y su filosofía de base - o en los debates analíticos y fenomenológicos acerca de la cuestión de la identidad, sería posible descubrir a los protagonistas que encarnan cada una de estas posiciones y, de esta forma, comprender algún aspecto de sus respectivas inspiraciones. Pero esta hipótesis, sólo esbozada aquí, debería ser justificada en otro estudio".

\section{Bibliografía}

Adorno, Theodor, y Max Horkheimer. 1998. Dialéctica de la Ilustración. Fragmentos filosóficos. Madrid: Trotta.

Bloom, Paul. 2016. Against empathy: The case for rational compassion. New York: Harper Collins.

Butler, Judith. 2009. Dar cuenta de sí mismo. Violencia ética y responsabilidad. Buenos Aires: Amorrortu.

Crosby, John. 1996. The Selfhood of the Human Person. Washington DC: CUA Press. Deleuze, Gilles y Guattari, Félix. 1985. El Anti Edipo. Capitalismo y esquizofrenia. Barcelona: Paidós.

Derrida, Jacques. 1986. De la gramatología. México: Siglo XXI.

Esposito, Roberto. 2009. Tercera persona. Política de la vida y filosofía de lo impersonal. Buenos Aires: Amorrortu.

Foucault, Michel. 2009. El gobierno de sí y de los otros. Curso en el College de France: 1982-1983. Buenos Aires: Fondo de Cultura Económica.

Foucault, Michel. 2010. El coraje de la verdad: El gobierno de sí y de los otros II. Curso en el College de France: (1983-1984). Buenos Aires: Fondo de Cultura Económica.

El autor es Becario del Instituto de Filosofía de la Universidad Austral en el Doctorado en Filosofía, con Orientación en Fundamentos de las Ciencias Naturales y Cognitivas. Esta publicación fue posible gracias a un subsidio de la John Templeton Foundation. Las opiniones expresadas en esta publicación son del autor y no necesariamente reflejan las de la John Templeton Foundation. This publication was made possible through the support of a grant from the John Templeton Foundation. The opinions expressed in this publication are those of the author and do not necessarily reflect the views of the John Templeton Foundation. 
Foucault, Michel. 1994. "L'éthique du souci de soi comme pratique de la liberté." En Dits et écrits (1954-1988), t. lV (1980-1988). Paris: Gallimard.

Freud, Sigmund. [1917] 2003. "Una dificultad del psicoanálisis.” En Obras Completas. Tomo III. Traducido por Luis López-Ballesteros y de Torres, 2432-2436. Buenos Aires: El Ateneo.

Giacon, Carlo. 1946. La Seconda Scolastica. v. II. Precedenze teoretiche ai problemi giuridici. Toledo, Pereira, Fonseca, Molina, Suárez. Milano: Fratelli Bocca.

Heidegger, Martin. 2000. Carta sobre el humanismo. Madrid: Alianza.

Heidegger, Martin. 2013. Nietzsche. Barcelona: Ariel.

Heidegger, Martin. 1997. Ser y tiempo. Traducido por Jorge Eduardo Rivera C. Santiago de Chile: Editorial Universitaria.

Herman, Arthur. 1998. La idea de decadencia en la Historia Occidental. Barcelona: Andrés Bello.

Kant, Immanuel. [1803] 2009. Sobre pedagogía. Córdoba: Universidad Nacional de Córdoba - Encuentro Grupo Editor.

Pinker, Steven. 2018. En defensa de la Ilustración. Por la razón, la ciencia, el humanismo y el progreso. Barcelona: Paidós.

Pinker, Steven y Paul Bloom. 1990. “Natural language and natural selection.” Behavioral and brain sciences 13: 707-784.

Ricoeur, Paul. 2006. “La identidad personal y la identidad narrativa.” En El sí mismo como otro. México: Siglo XXI.

Roldán, Juan Pablo. 2019. “Tres momentos, una idea. Un concepto filosófico acerca del desarrollo del ser humano presente en la psicología contemporánea”. Humanidades: revista de la Universidad de Montevideo 5: 53-79

Scheler, Max. 2003. El puesto del hombre en el cosmos. Buenos Aires: Losada.

Scheler, Max. 2004. Esencia y formas de la simpatía. Buenos Aires: Losada.

Schopenhauer, Arthur. 2008. El mundo como voluntad y representación. Buenos Aires: Losada.

Stein, Edith. 1998. La estructura de la persona. Madrid: BAC.

Vattimo, Gianni. 1996. Creer que se cree. Buenos Aires: Paidós.

Vattimo, Gianni. 1986. “El ocaso del sujeto y el problema del testimonio.” En Las aventuras de la diferencia. Pensar después de Nietzsche y Heidegger, 43-59. Barcelona: Península.

Vattimo, Gianni. 2004. Después de la cristiandad: por un cristianismo no religioso. Buenos Aires: Paidós.

Vattimo, Gianni. 2001. "Valores, consenso y «pensamiento débil». La fe en la libertad." Clarín. https://aprendizaje.mec.edu.py/dw-recursos/system/content/0c59c97/ content/Vattimo,\%20Gianni\%20(1936-XXXX)/Vattimo,\%20Gianni\%20-\%20El\%20 pensamiento\%20d\%C3\%A9bil.pdf 